\title{
The effects of the GABA agonist, baclofen, on sleep and breathing
}

\author{
A.J. Finnimore, M. Roebuck, D. Sajkov, R.D. McEvoy
}

\begin{abstract}
The effects of the GABA agonist, baclofen, on sleep and breathing. A.J. Finnimore, M. Roebuck, D. Sajkov, R.D. McEvoy. @ERS Journals Ltd 1995.

ABSTRACT: The gamma aminobutyric acid (GABA)-B agonist, baclofen, is a centrally-acting, anti-spasmodic agent and muscle relaxant used in spinal cord lesions, multiple sclerosis and other neurological disorders. In a previous pilot study of quadriplegic patients, $75 \%$ of whom were treated with baclofen, we found a high prevalence of sleep-disordered breathing. Because of the depressant effects of GABA on the central nervous system, we hypothesized that baclofen might aggravate sleepdisordered breathing in susceptible individuals by depressing central ventilatory drive, increasing upper airway obstruction and/or increasing the arousal threshold to apnoea.

We therefore conducted a double-blind, placebo-controlled, cross-over study of baclofen $25 \mathrm{mg}$, administered before sleep in 10 snorers with mild sleep-disordered breathing (respiratory disturbance index $<30$ events per sleep hour). Each subject underwent two standard polysomnographic assessments, one week apart.

Total sleep time was significantly prolonged by baclofen (placebo $356 \pm 9.9$ SEM min; baclofen $386 \pm 9.9 \mathrm{~min})$. Both nonrapid eye movement(REM) and REM sleep duration were increased (nonREM: placebo $295 \pm 6.8 \mathrm{~min}$; baclofen $311 \pm 8.9 \mathrm{~min}$; REM: placebo $61 \pm 7.5 \mathrm{~min}$; baclofen $76 \pm 9.0 \mathrm{~min}$ ). Time spent awake after sleep onset was reduced after baclofen (placebo $71 \pm 10.3 \mathrm{~min}$; baclofen $51 \pm 9.7 \mathrm{~min}$ ). There was a slight reduction in mean overnight oxygen saturation (placebo 95.2 $\pm 0.5 \%$; baclofen $94.4 \pm 0.7 \%$ ). The frequency of apnoeas plus hypopnoeas (respiratory disturbance index (RDI)) did not change significantly (placebo $9 \pm 1.8$ events $\cdot h^{\cdot-1}$; baclofen $13 \pm 3.4$ events $\left.\cdot h^{\cdot-1}\right)$.

We conclude that a single, therapeutic dose of baclofen alters sleep architecture and produces a small reduction in mean sleep oxygen saturation, but does not significantly increase sleep-disordered breathing.
\end{abstract}

Eur Respir J., 1995, 8, 230-234.

Sleep Disorders Unit, Repatriation General Hospital, Daw Park, South Australia.

Correspondence: R.D. McEvoy

Sleep Disorders Unit

Repatriation General Hospital

Daws Rd

Daw Park

South Australia 5041

Australia

Keywords: Baclofen

gamma aminobutyric acid

quadriplegia

sleep apnoea syndrome

sleep stages

Received: October 201993

Accepted after revision November 241994

This work was supported by a grant from the Julia Farr Centre Inc. Research Foundation.
Baclofen is a centrally-acting gamma aminobutyric acid (GABA)-B agonist with muscle relaxant and antispasmodic properties. It is widely used in the treatment of painful spasms in patients with spinal cord lesions, multiple sclerosis and other neurological disorders [1]. It has also been used experimentally to treat periodic limb movements during sleep [2]. GABA is a neurotransmitter with mainly inhibitory effects in the central nervous system and appears to decrease central ventilatory drive. It has been shown to decrease ventilation and ventilatory responsiveness to hypercapnia in experimental animals [3-5], and is a putative mediator of hypoxic ventilatory depression [6].

In a preliminary study, we found a high prevalence of significant nocturnal hypoxia in quadriplegic patients [7]. Subsequent polysomnographic studies of 40 quadriplegics from the same population (unpublished data) have shown a high prevalence of obstructive sleep apnoea (OSA); which concurs with the results of preliminary studies reported by other groups [8-10]. We conducted a survey of quadriplegic patients in South Australia, and found that $75 \%$ were treated with baclofen at an average evening dose of $30 \mathrm{mg}$ (range 10-50 mg); whereas, other anti-spasmodic agents were used less frequently (diazepam, 5-10 mg nocte in 58\%, and dantrolene in 28\%). It seemed important, therefore, to objectively assess the effects of baclofen on breathing during sleep.

We hypothesized that the adverse effects of baclofen on respiratory control would be most evident during sleep, especially in patients with a pre-existing tendency to sleep-disordered breathing. Because of its muscle relaxant properties, baclofen could increase the tendency to upper airway collapse during sleep and increase obstructive apnoeas (e.g. in snorers); whilst its depressant effect on respiratory drive might lead to central apnoeas or sleep hypoventilation. We report a double-blind, placebocontrolled study of baclofen in 10 otherwise healthy snorers with mild sleep-disordered breathing. 


\section{Methods}

\section{Subjects}

Ten volunteers (nine males and one female) were recruited from our Sleep Clinic population. Each of the volunteers was a chronic snorer and had been referred for polysomnography for the investigation of obstructive sleep apnoea (OSA). For inclusion in the study, they had to meet the following criteria: 1) apnoea index (AI) of $\leq 5$ apnoeas $\cdot \mathrm{h}^{-1}$ of sleep; 2) respiratory disturbance index (RDI; apnoeas + hypopnoeas) 5-30 events $\cdot \mathrm{h}^{-1}$ of sleep; and 3) nadir $\mathrm{O}_{2}$ saturation greater than $70 \%$. We deliberately chose patients who had mild OSA to reduce the risk of a serious exacerbation following baclofen, but at the same time we postulated that this would allow any adverse effect of the drug to be detected and quantified. All subjects were informed of the purpose of the study and gave informed consent by signing a consent form that had previously been approved by the Research and Ethics Committee of the Repatriation General Hospital, Daw Park.

Subjects were asked to refrain from the use of alcohol or caffeine for $8 \mathrm{~h}$ prior to testing and from smoking for at least $1 \mathrm{~h}$ before and during each sleep study. The subjects ranged 26-70 yrs in age and had no concomitant diseases, with the exception of controlled hypertension. They were asked to keep their normal sleepwake schedule for at least 3 days before the sleep study. Other exclusion criteria were acute respiratory tract infection, or concurrent treatment with sedatives or muscle relaxants.

Anthropometric and relevant diagnostic sleep study results for the selected subjects are shown in table 1 .

\section{Experimental Design}

A dose of $25 \mathrm{mg}$ baclofen (Lioresal, Ciba Geigy) or placebo was administered $2 \mathrm{~h}$ before the start of the sleep study. The kinetics of baclofen are such that by $10 \mathrm{~h}$ after ingestion serum levels are clinically insignificant. In healthy adults, the half-life (T1/2) is $3.8 \mathrm{~h}$ [11]. Repeated dosing on an 8 hourly schedule leads to only a minor rise in peak serum levels [12]. We considered, therefore, that use of a single nocturnal dose equal in size to the average dose used by our quadriplegic patients was clinically relevant, and should have enabled a pharmacological effect on sleep and breathing to be demonstrated if such an effect existed.

Each subject had adapted to the sleep laboratory during the diagnostic sleep study. For the present study they underwent two additional polysomnographic measurements one week apart. The order of administration of active drug or placebo ( $25 \mathrm{mg}$ lactose) was random and double-blinded. Drug and placebo could not be distinguished in appearance, both being placed inside an opaque gelatine capsule.

\section{Protocol}

Sleep recordings were made using a computerized data acquisition system (Sleepwatch, Compumedics, Melbourne, Australia). Monitored variables included: electroencephalogram (EEG) (C3/A2 or C4/A1), oronasal airflow (Compumedics thermistor), chin electromyogram (EMG), electrocardiogram (2 leads ECG), pulse oximetry oxygen saturation $\left(\mathrm{SpO}_{2}\right.$; Criticare 504 pulse oximeter, Waukesha, Wi, USA), leg movements (movement sensors, Compumedics) and body position (mercury switch position sensor, Compumedics). Respiratory movements of the chest and abdomen were monitored with an impedance plethysmograph (Vitalog, Ca, USA). A high digital sampling speed was used: $125 \mathrm{~Hz}$ for EEG and EMG; $50 \mathrm{~Hz}$ for electro-oculogram (EOG), ECG and leg movements; $10 \mathrm{~Hz}$ for respiratory movements and nasal thermistor; and $5 \mathrm{~Hz}$ for $\mathrm{Spo}_{2}$. Data were displayed on a high resolution 20 inch monitor (NEC multisync 6FG, Tokyo, Japan). Twenty seconds of real time data were displayed per screen for visual scoring of sleep stages, and 5 min per screen for visual scoring of respiratory events. Automatic analysis was used only to compute

Table 1. - Anthropometric data and results from diagnostic sleep study

\begin{tabular}{|c|c|c|c|c|c|c|}
\hline $\begin{array}{l}\text { Patient } \\
\text { No. }\end{array}$ & $\begin{array}{l}\text { Age } \\
\text { yrs }\end{array}$ & BMI & Sex & $\underset{\mathrm{SaO}_{2} \%}{\text { Minimum }}$ & $\begin{array}{l}\text { RDI (total) } \\
\text { events } \cdot \mathrm{h}^{-1}\end{array}$ & 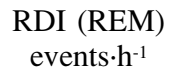 \\
\hline 1 & 26 & 32 & $\mathrm{M}$ & 82 & 14 & 31 \\
\hline 2 & 53 & 32 & $\mathrm{M}$ & 89 & 20 & 23 \\
\hline 3 & 49 & 27 & $\mathrm{M}$ & 90 & 11 & 41 \\
\hline 4 & 70 & 18 & M & 74 & 17 & 40 \\
\hline 5 & 68 & 29 & $\mathrm{M}$ & 83 & 12 & 39 \\
\hline 6 & 29 & 21 & $\mathrm{M}$ & 87 & 5 & 2 \\
\hline 7 & 49 & 30 & $\mathrm{M}$ & 84 & 22 & 31 \\
\hline 8 & 44 & 21 & $\mathrm{~F}$ & 86 & 15 & 13 \\
\hline 9 & 42 & 31 & $\mathrm{M}$ & 87 & 29 & 40 \\
\hline 10 & 48 & 21 & $\mathrm{M}$ & 90 & 14 & 16 \\
\hline Mean & 47.8 & 26.2 & & 85.2 & 15.9 & 27.6 \\
\hline SEM & 4.5 & 1.7 & & 1.5 & 2.1 & 4.3 \\
\hline
\end{tabular}

BMI: body mass index; RDI: respiratory disturbance (apnoea + hypopnoea) index; M: male; F: female; $\mathrm{SaO}_{2}$ : arterial oxygen saturation; REM: rapid eye movement. 
the average and minimum values of $\mathrm{SpO}_{2}$ for each (manually scored) sleep stage.

Sleep recordings were scored blind by a single observer. Sleep scoring (20 s epochs) was performed according to the criteria of REChtSCHAFFEN and Kales [13]. Hypopnoea was defined as a $50 \%$ or greater decrease from baseline in abdominal and thoracic excursions and/or airflow lasting for $10 \mathrm{~s}$ or more. Apnoea was defined as cessation of air flow for $10 \mathrm{~s}$ or more and characterized as obstructive, mixed or central. Sleep-disordered breathing was quantitated by calculating apnoea index (AI; apnoeas $\cdot h^{-1}$ of sleep), respiratory disturbance index (RDI, apnoeas plus hypopnoeas $\cdot h^{-1}$ of sleep) and $\mathrm{O}_{2}$ saturation (nadir and average).

\section{Statistics}

The paired Student's t-test was used to compare mean data for placebo and baclofen nights. The Chi-squared test was used to examine the difference in the relative prevalence of various types of apnoea between placebo and baclofen nights. The p-values reported are based on a two-tailed test; a p-value below 0.05 was considered statistically significant. Results are expressed as means \pm SEM.

\section{Results}

Sleep architecture data are presented in table 2. Total sleep time (TST) was increased significantly with baclofen treatment. Rapid eye movement (REM) sleep increased as a percentage of TST, as well as in absolute duration. The duration of nonREM sleep, but not slow-wave sleep (i.e. Stages 3 and 4), also increased slightly. The increase in TST was due equally to an increase in duration of REM sleep and of Stages 1 and 2 nonREM. Time awake after sleep onset was decreased after baclofen. No significant differences occurred on the baclofen night in the frequency of arousals, sleep efficiency, sleep latency, or the time available for sleep (lights out time).

A consequence of the randomization was that seven patients received baclofen on the second night of the study and only three received it on the first study night. Since significant differences were shown in a number of key sleep variables between baclofen and placebo nights and sleep efficiency may improve in sequential night sleep studies, a separate analysis looking for an order
Table 2. - The effect of baclofen on sleep architecture

\begin{tabular}{lcc}
\hline & Placebo & Baclofen \\
\hline Total sleep time min & $356 \pm 9.9$ & $386 \pm 9.9^{* * *}$ \\
Lights out time min & $424 \pm 10.2$ & $442 \pm 8.0$ \\
Sleep onset latency min & $6.3 \pm 1.7$ & $8.5 \pm 2.2$ \\
Time awake after sleep & $71 \pm 10.3$ & $51 \pm 9.7^{*}$ \\
$\quad$ onset min & & \\
NonREM duration min & $295 \pm 6.8$ & $311 \pm 8.9^{*}$ \\
NonREM \% Total & $83 \pm 1.8$ & $81.5 \pm 2.1^{*}$ \\
$\quad$ sleep time & & \\
Stages 1 and 2 & $240 \pm 11.0$ & $260 \pm 8.9^{* *}$ \\
$\quad$ duration min & $55 \pm 9.9$ & $51 \pm 8.9$ \\
Stages 3 and 4 & & \\
$\quad$ duration min & $61 \pm 7.5$ & $76 \pm 9.0^{* *}$ \\
REM duration min & $17 \pm 1.8$ & $20 \pm 2.1^{*}$ \\
REM \% Total sleep time & & $97 \pm 19.8$ \\
REM latency min & $79 \pm 16.2$ &
\end{tabular}

Values shown are mean \pm SEM. REM: rapid eye movement; Ns: nonsignificant. ${ }^{*}, * *, * * *: \mathrm{p}<0.05,0.02,0.001$, two-tailed paired t-test.

effect was undertaken. No order effect could be shown for any of the sleep variables; however, such an effect can not be entirely excluded because of the small study population.

Data on sleep-disordered breathing are presented in table 3. Mean pulse oximetry oxygen saturation $\left(\mathrm{Spo}_{2}\right)$ for total sleep was significantly reduced after baclofen, and for nonREM the difference approached statistical significance. There were no statistically significant differences in RDI, or minimum $\mathrm{SpO}_{2}$ following baclofen, although there was a trend toward an increase in RDI and a decrease in minimum $\mathrm{SpO}_{2}$ in nonREM sleep. Apnoea index was low and did not differ between the study nights (placebo $1.4 \pm 0.5$ apnoea $\cdot \mathrm{h}^{-1}$, baclofen $3.8 \pm 2.0$ apnoea $\cdot h^{-1}$; NS). No change in the ratio of the various apnoea types was observed after baclofen (obstructive: mixed: central apnoeas: placebo 1:0.1:0.6; baclofen 1:0.5: 0.5 ; Ns). Apnoea and hypopnoea durations did not differ on the study nights (mean apnoea+hypopnoea duration: placebo 16.2 $\pm 1.3 \mathrm{~s}$; baclofen $16.6 \pm 1.2 \mathrm{~s}$; NS).

\section{Discussion}

The findings of this study were that a standard dose of baclofen, administered at night to snorers with mild sleep-disordered breathing, altered sleep architecture and

Table 3. - The effect of baclofen on sleep disordered breathing

\begin{tabular}{|c|c|c|c|c|c|c|c|c|c|}
\hline & \multicolumn{3}{|c|}{ Total sleep } & \multicolumn{3}{|c|}{ nonREM } & \multicolumn{3}{|c|}{ REM } \\
\hline & $\begin{array}{c}\text { RDI } \\
\text { events } \cdot h^{-1}\end{array}$ & $\begin{array}{c}\mathrm{Spo}_{2} \\
\% \text { mean }\end{array}$ & $\begin{array}{c}\mathrm{SpO}_{2} \\
\% \text { min }\end{array}$ & $\begin{array}{c}\text { RDI } \\
\text { events } \cdot h^{-1}\end{array}$ & $\begin{array}{c}\mathrm{SpO}_{2} \\
\% \text { mean }\end{array}$ & $\begin{array}{l}\mathrm{SpO}_{2} \\
\% \mathrm{~min}\end{array}$ & $\begin{array}{c}\text { RDI } \\
\text { events.h-1 }\end{array}$ & $\begin{array}{c}\mathrm{SpO}_{2} \\
\% \text { mean }\end{array}$ & $\begin{array}{c}\mathrm{Spo}_{2} \\
\% \text { min }\end{array}$ \\
\hline Placeb & $8.7 \pm 1.8$ & $95.2 \pm 0.5$ & $87.6 \pm 2.1$ & $7.1 \pm 1.9$ & $95.3 \pm 0.5$ & $88.7 \pm 2.0$ & $15.8 \pm 4.1$ & $94.7 \pm 0.6$ & $87.9 \pm 2.1$ \\
\hline Baclofen & $12.8 \pm 3.4$ & $94.4 \pm 0.7$ & $83.9 \pm 2.9$ & $12.5 \pm 3.6$ & $94.5 \pm 0.7$ & $85.0 \pm 2.7$ & $13.7 \pm 3.6$ & $93.9 \pm 0.9$ & $85.4 \pm 2.9$ \\
\hline p-value* & 0.161 (Ns) & 0.032 & 0.107 (NS) & 0.097 (NS) & 0.053 (NS) & 0.085 (NS) & 0.574 (Ns) & 0.077 (NS) & $0.143(\mathrm{NS})$ \\
\hline
\end{tabular}

Data are presented as mean \pm SEM. $\mathrm{Spo}_{2}$ : pulse oximetry oxygen saturation. For further abbreviations see legends to tables 1 and 2. *: two-tailed paired t-test. 
produced a minor decrease in oxygen saturation during sleep, without an increase in sleep apnoeas or hypopnoeas. Baclofen appeared to have a sedative effect. Total sleep time, duration of REM and nonREM sleep, and the proportion of sleep spent in nonREM were increased. The increase in nonREM sleep was due to an increase in duration of Stages 1 and 2 and not Stages 3 and 4 (delta sleep). Time awake after sleep onset was reduced by $28 \%$. These findings are in agreement with those of a recent study of patients with periodic limb movements in sleep, in which $20 \mathrm{mg}$ of baclofen increased the duration of total sleep and REM sleep but did not change the amount of delta sleep [2].

Baclofen produced a small but significant reduction in mean $\mathrm{SpO}_{2}$ during sleep. Because the total time spent in apnoea/hypopnoea was very short compared with total sleep time and because there was no significant increase in disordered breathing events following baclofen, it can be inferred that the reduction in mean $\mathrm{SpO}_{2}$ resulted from a reduction in baseline sleep $\mathrm{Spo}_{2}$. The most likely explanation for this reduction is a fall in resting ventilation. GABA has been shown to decrease ventilation and ventilatory responsiveness to $\mathrm{CO}_{2}$ in the rat [3], and to have a similar ventilatory depressant effect in the dog [4] and cat [5].

There was no significant increase in the frequency of disordered breathing events for sleep overall, or for either REM or nonREM sleep. However, it is known that there is considerable night-to-night variability in RDI in patients with mild sleep-disordered breathing [14], such as those enrolled in the present study. The question arises, therefore, as to whether or not there was sufficient statistical power in our study to detect an important difference in sleep-disordered breathing after baclofen, had such a change occurred. The night-to-night coefficient of variation in RDI (diagnostic vs placebo study nights) was relatively high $(33 \%)$, as expected. However, we calculated [15] that given this variance and our sample size of 10 we would have been able to detect a real difference in RDI of $48 \%$ or greater (study power of $90 \%$ and two-tailed significance level of 0.05). That is, in the present study, we should have been able to detect a real increase in mean RDI from say 9 (the approximate mean RDI on placebo night) to 13.5. We argue that a change in mean RDI of less than this would not be clinically important in such a population, and, therefore, that our study had sufficient statistical power to detect meaningful changes in sleep-disordered breathing after baclofen, had such changes been present.

Apnoea and hypopnoea duration was not increased following baclofen in our study. Since most disordered breathing events during sleep are terminated by an arousal from sleep, this implies that sedation from $25 \mathrm{mg}$ of baclofen is not sufficient to increase arousal threshold.

We know of no other study of the effects of baclofen on sleep-disordered breathing. However, both alcohol and benzodiazepines, which exert their effects at least in part through GABA-ergic pathways [16-18], have been shown to increase sleep-disordered breathing in susceptible populations [19-21].

It is possible that clinically significant increases in sleep-disordered breathing may be observed in patients who have a greater underlying tendency to sleep-disordered breathing, patients given higher doses of baclofen, or patients on chronic treatment. Changes in sleep architecture at higher doses, however, would not necessarily predispose to more sleep-disordered breathing. Firstly, a decrease in the amount of REM sleep at high dosage, as shown elsewhere [2], would tend to mitigate against a worsening of apnoea. Secondly, whilst slow-wave sleep is increased at high doses of baclofen [2], studies with gamma hydroxybutyrate, a GABA metabolite known to also promote slow-wave sleep, failed to alter RDI in patients with OSA [22].

Baclofen is widely used in patients with neurological disorders, such as multiple sclerosis and spinal cord injuries, to treat painful muscle spasms. A number of such patients have altered upper airway or respiratory function as a result of their neurological disease, and are, therefore, prone to sleep-disordered breathing. Our data suggest that baclofen administration in such patients is safe if underlying sleep-disordered breathing is mild. We and other investigators [7-10] have previously shown that quadriplegic patients are prone to sleep apnoea and moderately severe episodic oxygen desaturation in sleep. The results of the present study suggest that baclofen administration alone is unlikely to be the explanation for these observations.

In conclusion, a small dose of the GABA agonist baclofen at night has been shown to increase total sleep time, prolong REM sleep and Stages 1 and 2 nonREM sleep, and reduce the time spent awake after sleep onset. Baclofen decreased mean nocturnal oxygen saturation slightly, but had no significant effect on the frequency of sleep-disordered breathing events in a susceptible population of snorers.

\section{References}

1. Reynolds JEF, ed. Martindale. The Extra Pharmacopoeia. 29 edn. London, Pharmaceutical Press, 1989; pp. 1230-1231.

2. Guilleminault C, Flagg W. Effect of baclofen on sleep related periodic limb movements. Ann Neurol 1984; 15: 234-239.

3. Hedner J, Hedner T, Wessberg P, Jonason J. An analysis of the mechanism by which GABA depresses ventilation in the rat. $J$ Appl Physiol: Respiration Environ Exercise Physiol 1984; 56: 849-856.

4. Kneussl MP, Pappagianopoulos P, Hoop B, Kazami H. Reversible depression of ventilation and cardiovascular function by ventliculocisternal perfusion with gammaaminobutyric acid in dogs. Am Rev Respir Dis 1986; 133: 1024-1028.

5. Yamada KA, Hamosh P, Gillis RA. Respiratory depression produced by activation of GABA receptors in hind brain of cat. J Appl Physiol: Respiration Environ Exercise Physiol 1981; 51: 1278-1286.

6. Neubauer JA, Melton JE, Edelman NH. Modulation of respiration during brain hypoxia. J Appl Physiol 1990; 68: $441-451$.

7. Flavell H, Marshall R, Thornton AT, Clements PL, Antic R, McEvoy RD. Hypoxia episodes during sleep 
in high tetraplegia Arch Phys Med Rehabil 1992; 73(7): 623-627.

8. Callall C, Gothe B, Decker MJ, Arnold JL, Strohl KP. Arterial oxygen saturation over time and sleep studies in quadriplegic patients. Paraplegia 1993; 31: 172-179.

9. Braun SR, Giovannoni BA, Levin AB, Halvey RF. Oxygen saturation during sleep in patients with spinal cord injury. Am J Phys Med 1982; 61: 302-309.

10. Bonekat HW, Andersen G, Squires J. Obstructive disordered breathing during sleep in patients with spinal cord injury. Paraplegia 1990; 28: 392-398.

11. Hulme A, MacLennan WJ, Ritchie RT, John VA, Shotton PA. Baclofen in the elderly stroke patient: its side-effects and pharmokinetics. Eur J Clin Pharmacol 1985; 29: 467-469.

12. Peterson G, McLean S, Millingen K. Food does not affect the bioavailability of baclofen. Med J Aust 1985; 142: 689-690.

13. Rechtschaffen A, Kales A. A manual of standardised terminology, techniques and scoring system for sleep stages of human subjects. Los Angeles, Brain Information Service/ Brain Research Institute, UCLA, 1968.

14. Wittig RM, Romaker A, Zorick FJ, Roehms T, Conway WA, Roth T. Night-to-night consistency of apneas during sleep. Am Rev Respir Dis 1984; 129: pp. 244-246.
15. Dobson AT. Transactions of the Menzies Foundation. Vol. 1. 1984; pp.75-79.

16. Ticku MK. Alcohol and GABA benzodiazepine receptor function. Ann Med 1990; 22: 241-246.

17. Allan AM, Burnett D, Harris RA. Ethanol-induced changes in chloride flux are mediated by both GABA (A) and GABA (B) receptors. Alcohol Clin Exp Res 1991; 15(2): 233-237.

18. Gaillard JM. Benzodiazepines and GABA-ergic Transmission. In: Kryger MH, Roth T, Dement WC, eds. Principles and Practice of Sleep Medicine. Philadelphia, W.B.Saunders, 1989; pp. 213-214.

19. Taasan VC, Block AJ, Boysen PG, et al. Alcohol increases sleep apnea and oxygen desaturation in asymptomatic men. Am J Med 1981; 71: 240-245.

20. Issa FG, Sullivan CE. Alcohol, snoring and sleep apnea. J Neurol Neurosurg Psychiatry 1982; 45: 353-359.

21. Dolly FR, Block AJ. Effect of flurazepam on sleepdisordered breathing and nocturnal oxygen desaturation in asymptomatic subjects. Am J Med 1982; 73: 239243.

22. Series F, Series I, Cormier Y. Effects of enhancing slow-wave sleep by gamma hydroxybutyrate on obstructive sleep apnea. Am Rev Respir Dis 1992; 145: 13781383. 